\title{
REGULASI SANITASI MAKANAN DI KANTIN MADRASAH IBTIDAIYAH KOTA BANDAR LAMPUNG TAHUN 2020
}

\author{
Food Sanitation Regulation In The Canteen Of Madrasah Ibtidaiyah, Bandar \\ Lampung City 2020
}

\author{
Derius Ixroni $^{1}$, Dina Dwi Nuryani ${ }^{2}$, Christin Angelina Febriani ${ }^{3}$ \\ ${ }^{1}$ Fakultas Kesehatan Masyarakat Universitas Malahayati Bandar lampung \\ ${ }^{2}$ Program Studi Ilmu Kesehatan Masyarakat Universitas Malahayati Bandar Lampung \\ ${ }^{3}$ Program Studi Kesehatan Lingkungan Universitas Malahayati Bandar Lampung
}

\begin{abstract}
Abstrak
Sebanyak 2.897 orang mengalami Kejadian Luar Biasa (KLB) keracunan dan 1.661 orang diantaranya sakit. Penyebab KLB ditinjau dari jenis pangan siap saji pada tahun 2018 sebanyak 33,93\%. Data keracunan pangan dilihat dari kabupaten/kota yaitu 150 kasus keracunan di kota Bandar Lampung. Tujuan penelitian ini untuk mengetahui Regulasi Sanitasi Makanan Di Kantin Madrasah Ibtidaiyah Kota Bandar Lampung Tahun 2020. Penelitian ini menggunakan metode diskriptif kualitatif untuk mengetahui penerapan regulasi sanitasi makanan di kantin Madrasah Ibtidaiyah kota Bandar Lampung, dilakukan di 5 Madrasah Ibtidaiyah yang ada di kota Bandar Lampung yaitu MIN 3, MIN 6, MIN 9, MI Hidayatul dan MI Ismaria. Jenis data yang digunakan ialah data primer dengan observasi dan wawancara mendalam, serta data sekunder yaitu telaah dokumen Madrasah yang berkaitan dengan regulasi sanitasi makanan. Disimpulkan bahwa Madrasah Ibtidaiyah Kota Bandar Lampung sudah menerapkan regulasi sanitasi makanan di kantin dan sebagian madrasah membuat peraturan secara tertulis serta mengimplementasikan regulasi sanitasi makanan dengan mensosialisasikan kepedagang kantin. Penanggungjawab kantin juga melakukan pemantauan untuk bahan makanan, penyimpanan bahan makanan, penyimpanan makanan yang telah dimasak serta cara penyajian makanan tersebut.
\end{abstract}

Kata Kunci : Sanitasi makanan, Implementasi Regulasi Sanitasi Makanan, Kantin

\begin{abstract}
A total of 2,897 people experienced extraordinary events (KLB) of poisoning and 1,661 of them were sick. The causes of KLB in terms of types of ready-to-eat food in 2018 were $33.93 \%$. Food poisoning data can be seen from districts / cities, namely 150 cases of poisoning in the city of Bandar Lampung. The purpose of this study was to determine the Food Sanitation Regulation in the Madrasah Ibtidaiyah Canteen in Bandar Lampung City in 2020. This study used a qualitative descriptive method to determine the application of food sanitation regulations in the Madrasah Ibtidaiyah canteen in Bandar Lampung, conducted at 5 Madrasah Ibtidaiyah in the city of Bandar Lampung, namely MIN 3, MIN 6, MIN 9, MI Hidayatul and MI Ismaria. The types of data used are primary data with in-depth observation and interviews, and secondary data, namely review of Madrasah documents related to food sanitation regulations. It was concluded that Madrasah Ibtidaiyah Kota Bandar Lampung had implemented food sanitation regulations in canteens and some madrasas made written regulations and implemented food sanitation regulations by disseminating the canteen traders. The person in charge of the canteen also monitors foodstuffs, stores foodstuffs, stores cooked food and how the food is served.
\end{abstract}

Keywords: Food sanitation, Implementation of Food Sanitation Regulations, Canteen

Korespondensi : Derius Ixroni

Email : ixroniderius@gmail.com 


\section{PENDAHULUAN}

Keracunan makanan dibagi menjadi dua yaitu racun secara alamiah dan racun dari luar yang mencemari makanan (1). Keracunan dapat menimbulkan gangguan gasterointestinal (GI) yang mendadak dalam waktu 2-40 jam setelah makan dengan menimbulkan gejala muntah-berak bahkan karena banyak racun yang tidak menimbulkan gejala gasterointestinal tetapi dapat menimbulkan gejala gangguan syaraf, ginjal dan lainnya. Keracunan bila mendapatkan pertolongan yang baik biasanya dapat sembuh dengan cepat (2). Gejalagejala keracunan makanan meliputi muntah - muntah, diare, nyeri (sakit) rongga dada dan perut serta demam. Diare adalah suatu kondisi dimana seseorang buang air besar dengan konsistensi lembek atau cair dan frekuensinya lebih dari tiga kali sehari (3). Konsekuensi lainnya dari diare pada anak-anak termasuk penurunan pertumbuhan, kekurangan gizi, dan gangguan kognitif pembangunan di negara berkembang (4). Keracunan makanan umumnya disebabkan oleh bakteri yang terdapat dalam makanan. Jumlah orang yang terpapar karena kejadian luar biasa akibat keracunan pangan sebanyak 2.897 orang dan 1.661 orang diantaranya sakit. Penderita keracunan makanan dengan kelompok dominan usia 8 tahun (5). Kebersihan makanan dan minuman, yang kurang baik dari 64 responden lebih banyak menderita foodborne disease dengan persentase sebesar $(77,8 \%)$ sedangkan yang tidak menderita foodborne disease sebesar terbanyak yang mengalami kejadian keracunan (54,5\%) (8). Berdasarkan 13 populasi 9 sampel penelitian ditinjau dari sanitasi peralatan makanan diketahui 33,3\% kantin telah memenuhi syarat pencucian peralatan,berdasarkan sanitasi penyajian kebersihan meja penyajian yang memenuhi syarat $44,4 \%$ dan yang tidak $55,6 \%$ di kantin SDN Kecamatan Mulyorejo (9). Sanitasi makanan adalah salah satu usaha pencegahan yang menitik beratkan kegiatan dan tindakan yang perlu untuk membebaskan makanan dan minuman dari segala bahaya yang dapat mengganggu kesehatan terutama gangguan pencernaan pada manusia yaitu keracunan. Sanitasi makanan pada dasarnya memiliki 6 prinsip dasar yaitu : Keadaan Bahan Makanan, Cara Penyimpanan Bahan Makanan, Proses Pengolahan, Cara Pengangkutan Makanan (Sarana), Cara Penyimpanan Makanan Masak dan Cara Penyajian Makanan Masak (10). Berdasarkan peraturan pemerintah nomor 19 tahun 2005 tentang standar nasional pendidikan pasal 42 sarana dan prasaranan ayat 2 menjelaskan setiap satuan pendidikan wajib memiliki prasarana contohnya seperti kantin atau ruang pendukung lainnya yang diperlukan untuk menunjang proses pembelajaran yang teratur dan berkelanjutan (11). Berdasarkan keputusan Menteri Kesehatan Republik Indonesia tentang penyelenggaraan kesehatan lingkungan sekolah tahun 2006 pasal 3 ayat 5 ruang bangunan kantin/warung 
$(22,3 \%)$ di sekolah dasar negeri Inpres

3 Tondo kota Palu (6). Penyebab Kejadian Luar Biasa (KLB) jika ditinjau dari jenis pangan tahun 2018 pangan jajanan/siap saji terjadi sebanyak 33,93\% dan berdasarkan tempat kejadian/lokasi KLB keracunan pangan lembaga pendidikan SD/MI terjadi sebanyak $28,57 \%$ kejadian (7). Penderita keracunan makanan adalah siswa di SD 3 Sangeh Kabupaten Badung yang mengkonsumsi makanan yang dibeli dikantin sekolah menurut jenis kelamin perempuan $(66,7 \%)$ dan laki-laki (33,3\%), sedangkan kelompok umur 9-10 tahun merupakan

\section{METODE PENELITIAN}

Jenis penelitian ini adalah kualitatif dengan survei analisis jabatan (Functional Analysis Survey). Survei ini bertujuan untuk mengetahui tugas dan tanggung jawab serta survei ini juga dapat mengetahui status dan hubungan antara satu dengan lainnya, mengetahui hubungan antara atasan dan bawahan dan fasilitas yang ada untuk melaksanakan tugas (13). Penelitian ini mengkaji secara mendalam implementasi Regulasi Sanitasi Makanan di Kantin Madrasah Ibtidaiyah Kota Bandar Lampung Tahun 2020.Penelitian ini telah dilakukan pada bulan April sampai dengan bulan Oktober di Madrasah Ibtidaiyah yang ada di kota Bandar Lampung tahun 2020. Subjek pada penelitian ini menggunakan penentuan informan dengan purposive sampling. Purposive sampling didasarkan pada pertimbangan tertentu yang dibuat oleh peneliti sendiri (14). Sumber data sekolah menjelaskan tersedia tempat cuci peralatan makan dan minum dengan air mengalir, tersedia tempat cuci tangan bagi pengunjung kantin, tersedia tempat penyimpan bahan makanan, tersedia tempat penyimpanan makanan jadi yang tertutup, tempat untuk penyimpanan peralatan makan dan minum serta lokasi kantin berjarak 20m dari tempat pembuangan sementara (12). Tujuan penelitian ini untuk mengetahui Regulasi Sanitasi Makanan Di Kantin Madrasah Ibtidaiyah Kota Bandar Lampung Tahun 2020.

Sedangkan data skunder melalui dokumen milik sekolah. Teknik pengumpulan data dalam penelitian kualitatif ada empat cara ialah observasi, wawancara, dokumentasi dan triangulasi (14). Dalam penelitian ini pengumpulan data lebih banyak pada observasi, wawancara mendalam dan dokumentasi.

Hasil wawancara dapat disimpulkan melalui satuan penilain. Peneliti menggunakan satuan penilaian terhadap pernyataan-pernyataan yang diungkapkan oleh informan (Informan Kunci, Utama dan Tringulasi sumber). Penelitian kualitatif yang menjadi instrumen atau alat penelitian adalah peneliti itu sendiri. Maka peneliti sebagai instrumen juga harus divalidasi untuk menguji kredibilitas data penelitian peneliti menggunakan teknik triangulasi. Dalam penelitian ini menggunakan triangulasi sumber untuk menguji kredibilitas data dilakukan dengan cara mengecek data 
penelitian ini didapat dari data primer dan data skunder. Data primer melalui observasi langsung dan wawancara mendalam (indept interview) dengan menggunakan pedoman wawancara yang memuat pokok-pokok yang akan ditanyakan untuk memperoleh keterangan secara lisan antara peneliti dengan informan.

\section{HASIL DAN PEMBAHASAN}

a. Keberhasilan Regulasi Sanitasi Makanan

Berdasakan hasil penelitian yang dilakukan bahwa Madrasah Ibtidaiyah Kota Bandar Lampung telah mengeluarkan kebijakan tentang regulasi sanitasi makanan di kantin namun hanya sebagian kecil Madrasah Ibtidaiyah Kota Bandar Lampung yang memiliki peraturan tertulis dibuktikan dengan dokumentasi yang terlampir dan sebagian besar Madrasah Ibtidaiyah Kota Bandar Lampung hanya membuat regulasi sanitasi makanan atas kebijakan dari tiap kepala Madrasah (Informan utama). Kebijakan tersebut disosialisasikan terhadap guru penanggungjawab kantin di Madrasah secara lisan dan pedagang kantin.

b. Implementasi Regulasi Sanitasi Makanan

Berdasarkan hasil penelitian yang dilakukan bahwa Madrasah Ibtidaiyah Kota Bandar Lampung mengimplikasikan regulasi sanitasi makanan dengan pengontrolan langsung kekantin setiap bulannya. Berdasarkan penjelasan dari sumber tringulasi bahwa kantin yang telah diperoleh melalui beberapa sumber (14). Pada penelitian ini, peneliti melakukan triangulasi sumber terhadap guru penanggung jawab kantin di madrasah ibtidaiyah kota Bandar Lampung dengan menggunakan teknik wawancara.

serta bahan makanan yang cepat rusak dan busuk harus disimpan dalam wadah yang terpisah. Kelayakan bahan makanan yang digunakan dapat juga dilihat dari tempat penyimpanannya, jika tempat penyimpanan bahan makanan saja tidak diperhatikan dengan baik maka dapat dipastikan bahwa makanan tersebut tidak layak di konsumsi.

e. Regulasi Proses Pengolahan Makanan

Berdasarkan hasil penelitian yang dilakukan bahwa Madrasah Ibtidaiyah Kota Bandar Lampung pengolahan makanan di kantin dengan menggunakan alat-alat yang bersih dan tidak terkontaminasi dengan debu. Ada beberapa makanan yang sudah di olah di rumah sehingga ketika di kantin hanya tinggal penyajiannya saja. Menurut hasil wawancara pengolahan makanan di kantin Madrasah sudah bersih. Menurut KEPMENKES RI No. 942 Tahun 2003 tentang Pedoman Persyaratan Higiene Sanitasi Makanan Jajanan, peralatan yang digunakan untuk mengolah dan menyajikan makanan jajanan harus sesuai dengan 
yang ada telah memenuhi kebersihan lingkungan kantin, makanan yang sehat, makanan yang tertutup dan layak untuk di konsumsi. Namun dari hasil analisis yang dilakukan peneliti dari keterangan yang didapatkan ternyata terdapat makanan yang masak hanya disimpan di keranjang makanan yang ditutupi kain karna masih sangat besar kemungkinan makanan terkontaminasi serangga dan debu.

c. Regulasi Keadaan Bahan Makanan

Berdasarkan hasil penelitian yang dilakukan bahwa Madrasah Ibtidaiyah Kota Bandar Lampung keadaan bahan makanan yang diolah di kantin menggunakan bahan makanan yang sehat dan aman dikonsumsi. Bahan makanan sehat dan aman yang dimaksud adalah tidak menggunakan pewarna makanan sintetis dan juga tidak menggunakan bahan pengawet makanan. Namun jika pedagang di kantin tersebut ingin menggunakan bahan tambahan pangan tidak dilarang, hanya saja bahan tambahan pangan yang digunakan tidak boleh melebihi batas penggunaan.

d. Regulasi Penyimpanan Bahan Makanan

Berdasarkan hasil penelitian yang dilakukan bahwa Madrasah Ibtidaiyah Kota Bandar Lampung penyimpanan bahan makanan di tempatkan pada wadah yang higienis juga tertutup rapat. Menurut KEPMENKES RI No. 942 Tahun 2003 tentang Pedoman peruntukannya dan memenuhi persyaratan higienesanitasi dan dilarang menggunakan kembali peralatan yang dirancang hanya untuk sekali pakai.

f. Regulasi Pengangkutan Makanan Dalam hal pengangkutan makanan peneliti hanya melakukan observasi saja dikarenakan penelitian ini dilakukan pada masa pandemi, jadi kurang memungkinkannya melihat secara langsung bagaimana pengangkutan makanan. Dari hasil wawancara yang ada mengenai beberapa prinsip yang sudah ditanyakan kepada pihak penanggungjawab sekolah, pengangkutan makanan masak maupun bahan makanan yang baru akan diolah sudah sesuai dengan standar sanitasi makanan. Pengangkutan untuk makanan masak mereka sudah menggunakan kemasan langsung dari rumah, dan untuk makanan masak mereka menggunakan wadah yang tertutup rapat untuk menghidari debu ketika dalam perjalanan dari rumah kesekolah.

g. Regulasi Penyimpanan Makanan Masak

Berdasarkan hasil penelitian yang dilakukan bahwa Madrasah Ibtidaiyah Kota Bandar Lampung penyimpanan makanan masak biasanya menggunakan wadah yang tertutup rapat. Selain tertutup rapat wadah makanan juga harus diberi ventilasi agar ketika makanan panas di tutup rapat uapnya akan keluar melalui ventilasi tersebut. Tujuannya agar makanan tersebut 
Persyaratan Higiene Sanitasi Makanan Jajanan, bahan makanan serta bahan tambahan makanan harus disimpan secara terpisah,

\section{KESIMPULAN DAN SARAN}

Berdasarkan hasil penelitian dan pembahasan tentang regulasi sanitasi makanan di kantin Madrasah Ibtidaiyah Kota Bandar Lampung Tahun 2020, dapat disimpulkan bahwa kantin Madrasah Ibtidaiyah Kota Bandar Lampung seluruhnya sudah memenuhi standar sanitasi keadaan bahan makanan, memenuhi standar sanitasi makanan adanya penyimpanan bahan makanan, melakukan proses pengolahan makanan menurut standar sanitasi makanan, melakukan pengangkutan makanan menurut standar sanitasi makanan, dan penyajian makanan menurut standar sanitasi makanan. Namun, untuk yang memenuhi standar penyimpanan makanan masak hanya sebagian kecil dari Madrasah Ibtidaiyah Kota Bandar Lampung. Untuk kepala sekolah membuat peraturan sanitasi makanan secara tertulis dan disosialisasikan kepada pedagang kantin. Untuk guru penanggung jawab kantin sebaiknya lebih sering untuk melakukan sosialisasi terhadap para pedagang tentang peraturan sanitasi makanan agar para pedagang

\section{DAFTAR PUSTAKA}

1. Sediaoetama, Djaelani A. Ilmu Gizi. 1989.

2. Slamet S. Kesehatan Lingkungan. Gadjah Mada University Press; 2000.

3. Irianto K. ANATOMI dan tidak terkontaminasi oleh air uap panas dari makanan tersebut.

kantin jadi semakin memperhatikan sanitasi makanan yang mereka jual. Untuk para pedagang dapat menggunakan bahan makanan dan bahan tambahan makanan yang sudah sesuai dengan PERMENKES yang ada agar makanan yang dijual layak konsumsi dan sehat, diharapkan lebih memperhatikan dan mengerti dengan jenis bahan makanan yang akan diolah serta cara penyimpanan masing-masing bahan makanan yang akan mereka olah, dapat menggunakan peralatan pengolahan makanan yang dapat dipakai jangka panjang dan menghindari penggunaan alat sekali pakai agar mengurangi sampah, menggunakan wadah penyimpanan makanan yang aman dan wadah yang digunakan menyesuaikan setiap jenis makanan juga suhu setiap makanan yang sudah diolah, dan untuk penyajian makanan yang akan dikonsumsi di tempatkan pada wadah yang berbeda agar makanan yang disajikan tidak saling tercemar satu sama lain.

1. Sediaoetama, Djaelani A. Ilmu Gizi. 1989.

2. Slamet S. Kesehatan Lingkungan. Gadjah Mada University Press; 2000.

3. Irianto K. ANATOMI dan FISIOLOGI. Bandung: Alfabeta; 2014. 
FISIOLOGI. Bandung: Alfabeta; 2014.

4. World Gastroenterology

Organisation. Practice guideline

for acute diarrhea in adults and children: A global perspective. World Gastroenterol Organ Glob Guidel. 2012;(February):3-4.

5. Dinas Kesehatan Kota Bandar Lampung. Riskedas Kota Bandar Lampung. Lampung; 2019.

6. Herman, Napirah, Sherlina D. Jurnal Herman dan Napirah. 2015;1(2):1-14.

7. Badan POM RI. Laporan Tahunan BPOM RI 2018. 2018;1-323.

8. Suarjana I., Agung AAG. Kejadian Luar Biasa Keracunan Makanan (Studi Kasus di SD 3 Sangeh Kabupaten Badung). J Skala Husada. 2013;10(2):144-8.

9. Syafirah S, D. R. A. Higiene Penjamah Makanan dan Sanitasi Kantin Sekolah Dasar Negeri di Kecamatan Mulyorejo. 2012;10:111-6.

10. Sumantri A. Kesehatan Lingkungan. Jakarta: Kencana Prenada Media Group; 2015.

11. Pemerintah RI. Peraturan Pemerintah No. 19 Tahun 2005. 2005;(1):1-5.

12. KEPMENKES.

Kepmenkes_2006.pdf. 2006.

13. Notoatmodjo S. Metodologi Penelitian Kesehatan. Jakarta: Rineka Cipta; 2012.

14. Sugiyono. METODE PENELITIAN. Sugiyono, editor. Bandung: PT Alfabeta; 2017.
4. World Gastroenterology Organisation. Practice guideline for acute diarrhea in adults and children: A global perspective. World Gastroenterol Organ Glob Guidel. 2012;(February):3-4.

5. Dinas Kesehatan Kota Bandar Lampung. Riskedas Kota Bandar Lampung. Lampung; 2019.

6. Herman, Napirah, Sherlina D. Jurnal Herman dan Napirah. 2015;1(2):1-14.

7. Badan POM RI. Laporan Tahunan BPOM RI 2018. 2018;1-323.

8. Suarjana I., Agung AAG. Kejadian Luar Biasa Keracunan Makanan (Studi Kasus di SD 3 Sangeh Kabupaten Badung). J Skala Husada. 2013;10(2):144-8.

9. Syafirah S, D. R. A. Higiene Penjamah Makanan dan Sanitasi Kantin Sekolah Dasar Negeri di Kecamatan Mulyorejo. 2012;10:111-6.

10. Sumantri A. Kesehatan Lingkungan. Jakarta: Kencana Prenada Media Group; 2015.

11. Pemerintah RI. Peraturan Pemerintah No. 19 Tahun 2005. 2005;(1):1-5.

12. KEPMENKES. Kepmenkes_2006.pdf. 2006.

13. Notoatmodjo S. Metodologi Penelitian Kesehatan. Jakarta: Rineka Cipta; 2012.

14. Sugiyono. METODE PENELITIAN. Sugiyono, editor. Bandung: PT Alfabeta; 2017. 